\title{
Accessibility and territorial cohesion in a case of transport infrastructure improvements with changing population distributions
}

\author{
Chris Jacobs-Crisioni $^{1}$ (D) - Filipe Batista e Silva ${ }^{1}$ - Carlo Lavalle $^{1}$ - Claudia Baranzelli ${ }^{1}$. \\ Ana Barbosa ${ }^{1}$. Carolina Perpiña Castillo ${ }^{1}$
}

Received: 20 August 2014 / Accepted: 10 February 2016/Published online: 20 February 2016

(C) The Author(s) 2016. This article is published with open access at SpringerLink.com

\begin{abstract}
Purpose In the last decade or so several studies have looked into the impacts of transport infrastructure improvements on decreasing territorial disparities. In those studies population levels are usually assumed static, although future population levels likely change in response to changing accessibility levels as well as to other factors. To test how much accessibility impacts may be affected by changes in population levels, this study explores the effects of foreseeable population changes on the accessibility improvements offered by large scale transport infrastructure investments.

Methods In this study we compare accessibility measures from four cases, namely the current situation; one case in which only transport investments are taken into account; and two cases that include transport investments and two scenarios with differing future population distributions that in turn are simulated by the LUISA land-use model. The modelled transport investments are assumed to improve travel times. The study concentrates on accessibility effects in Austria, Czech Republic, Germany and Poland. To provide a reference to the found results, the same computations are repeated with historical population and road network changes.

Results The results indicate that differences in local population levels have a limited effect on average accessibility levels,
\end{abstract}

This article is part of the Topical Collection on Accessibility and Policy Making

Chris Jacobs-Crisioni

christiaan.jacobs@ext.jrc.ec.europa.eu

1 European Commission, Joint Research Centre, Institute for Environment and Sustainability, Sustainability Assessment Unit, Via E. Fermi, 2749, 21027 Ispra (Va), Italy but may have a large impact on territorial inequalities related to accessibility.

Conclusions The findings in this study underpin the importance of incorporating future local population levels when assessing the impacts of infrastructure investments on territorial disparities.

Keywords Accessibility $\cdot$ Cohesion $\cdot$ Land-use modelling · Land-use/transport interaction

\section{Introduction}

Accessibility deals with the level of service provided by transport networks, given the spatial distribution of activities [1]. Improving accessibility is an important means to increase social and economic opportunities $[1,2]$ and accessibility considerations are deemed an important component of sustainable development [3]. In Europe, a substantial amount of public funding is dedicated to increase accessibility in peripheral and/or landlocked regions; in particular through the European Union's (EU) cohesion policy instruments [4]. The territorial cohesion aim of those policies is usually interpreted as the aim to decrease disparities between European regions [5]. To do so, the EU's cohesion policies provide funding for regionally tied projects in a wide range of sectors with the aim to "kick-start growth, employment, competitiveness, and development on a sustainable basis" [6, p. 13]. The regional investment program includes a considerable amount of funding available for transport infrastructure improvements; but funding is also available for other aims such as environmental protection, promoting tourism, and urban and rural regeneration.

To assess whether transport infrastructure improvements have the intended effect of decreasing disparities in 
accessibility among European regions, recent studies have employed sophisticated accessibility measures and inequality indicators $[5,7,8]$. The cohesion effects that those measures yield are varied, depending in particular on the analysed transport mode. In general, road link upgrades seem to increase territorial cohesion $[8,9]$, while in contrast high speed railway links accentuate differences in accessibility between regions $[5,7]$. Most accessibility measures are based on two dimensions: on the one hand the traveltime or generalized travel-cost needed to overcome geographic distance making use of available transport options; and on the other hand the spatial distribution of activities (commonly using GDP or population counts as a proxy). As is the case in all previously mentioned case studies, the effects of transport infrastructure improvements on accessibility are usually taken into account by known reductions in traveltime or generalized cost, while spatial activity distributions are often presumed static. However, the spatial distribution of activities is surely not static, and in fact adjusts to changing accessibility levels over time [10-12]. Thus, if spatial activity distributions adjust to changing accessibility levels, ex-ante evaluations of infrastructure studies may benefit from taking reciprocities with spatial activity distributions into account - for example to assess the robustness of found accessibility benefits with differing population growth scenarios, or to compose complementary spatial planning strategies that optimize the effectiveness of transport infrastructure investments.

Accessibility has received considerable attention in the literature. For example, the effect that accessibility improvements may have on activity distributions has been studied repeatedly [10-15]. Other studies have researched spill-over effects of transport infrastructure improvements $[8,16]$. The effect that spatial activity distributions may have on accessibility, as studied in this paper, has received less attention. Geurs and Van Wee [17] compared the land resource, accessibility and transport consumption impacts of the relatively compact post-war urban development in the Netherlands with the outcomes of alternate land-use planning policies. Their study shows slightly better aggregate accessibility levels as a result of compact development, mainly due to lower congestion levels. Wang et al. [18] compare accessibility levels and associated social welfare effects in Madrid with different transport policy measures, while explicitly modelling changes in transport behaviour and land-use patterns. Other studies in the Netherlands have also explored land-use impacts on accessibility $[19,20]$, which in general confirm that land-use policies may increase aggregate accessibility levels and that tailored spatial planning can increase the benefits of transport infrastructure investments.

All of the abovementioned studies focus on total or average accessibility changes, and it is still unclear to what degree the spatial redistribution of activities may affect disparities in accessibility, in particular in regions where general activity levels are decreasing. This article will add to the available literature by looking into how local population changes may affect found levels of territorial disparities in accessibility. Because of computational limitations the study at hand had to be limited to four countries. Austria, Czech Republic, Germany and Poland have been selected, because they make a spatially adjacent but mixed set of new and old member states that differ substantially in current levels of infrastructure endowment (with much larger endowments in Austria and Germany) and in levels of transport infrastructure investment funded by EU cohesion policies (with much more investment in Czech Republic and Poland). Results from four cases will be compared: a reference case that comprises the current road network and population distribution in Europe in 2006 (case I); a case in which population distributions are from 2006, but road network improvements are imposed that are assumed to gradually decrease travel times between 2006 and 2030 (case II); and two cases that consider the same road network improvements, as well as modelled future population distributions (Compact scenario: case III and Business As Usual or BAU scenario: case IV). The latter two cases assume identical regional population projections, but differ in assumed local spatial planning policies, and therefore have different intraregional population patterns. The modelled future road networks and population distributions are mostly based on well-documented and empirically tested relations, but to some extent rely on expert judgement, which in turn may raise doubts concerning their validity; a common problem for scenario approaches [21]. To provide some reference, this paper will compare the outcomes of relevant indicators with the same indicators computed for changes in observed population levels and accessibility levels between 1971 and 2011. We must nevertheless stress that past changes are not necessarily indicative of future changes. Furthermore, the uncertainties surrounding future projections are not problematic as long as the simulation outcomes are used for what they are: maps showing potential future developments, given many scenario-related assumptions.

\section{Methods}

The here presented results were produced in a land-use modelling exercise that aimed to look into how EU cohesion policies and other EU policies with spatial relevance may affect landuse, accessibility and a range of environmental indicators. The mentioned study is comprehensively documented in Batista $\mathrm{e}$ Silva et al. [22]. The study assumes a number of road network improvements funded by the EU's regional cohesion policy program for the years 2014 to 2020 . A part of those improvements is known in advance, and a part consists of modelled upgrades given available funding at regional level. Population redistributions are modelled using the European 
Commission's platform for Land-Use-based Integrated Sustainability Assessment (LUISA) [23]. In this section we will describe the used land-use modelling platform, the way by which cohesion policy impacts are modelled with it, and the applied methods to evaluate cohesion impacts of the modelled outcomes.

\subsection{The LUISA platform}

LUISA is a dynamic spatial modelling platform that simulates future land-use changes based on biophysical and socioeconomic drivers and is specifically designed to assess landuse impacts of EU policies. Its core was initially based on the Land Use Scanner [24, 25], CLUE and Dyna-CLUE land-use models [26-28], but its current form is the result of a continuous development effort by the Joint Research Centre [23] that owes much to the highly flexible GeoDMS [29] modelling software in which LUISA is implemented. LUISA downscales regional projected future land use demands to a fine spatial resolution and thus models changes in population and land use with reference to CORINE land-use/land-cover maps [30] and a fine resolution population distribution map [31]. It allocates land uses and population per year on a $100 \mathrm{~m}$ spatial grid. It discerns a number of land-use types, which can roughly be separated in urban, industrial, agricultural and natural land uses. The timeframe for which LUISA simulates landuse changes varies per study; for this study the model ran for the period from 2006 to 2030 .

As can be seen in Fig. 1, LUISA is structured in a demand module, a land-use allocation module and an indicator module. At the core of LUISA is a discrete allocation method that is doubly constrained by on the one hand projected regional land demands and on the other hand regional land supply. For an elaborate description of the land allocation method we refer to Hilferink and Rietveld [24] and Koomen et al. [25]. The regional land demands are provided in the demand module by sector-specific economic models, such as the CAPRI model for agricultural land demands [32] and the GEM-E3 model for industrial land demands [33]. Within its constraints, the model attempts to achieve an optimal land-use distribution based on spatially varying local suitabilities for competing land uses. Those suitability values for given land uses, in turn, are derived from fitting biophysical, socio-economic and neighbourhood factors on spatial land-use patterns with a multinomial discrete choice method. LUISA is run for each country independently. Its outcomes are population distributions, spatial land-use patterns and accessibility values for each of the model's time steps. Those outcomes are used to inform local suitability values in the next time step and to compute policy-relevant indicators of the impacts of land-use change in the indicator module. A broad range of indicators is computed within LUISA, of which cohesion effects of policy scenarios are particularly relevant for this paper.
Two recent additions to LUISA set it apart from similar land-use models. The first addition considers the parallel endogenous allocation of number of people to the model's $100 \mathrm{~m}$ grid, which is described here briefly; for a detailed overview see Batista e Silva et al. [22]. In LUISA's people allocation method, in each time step a region's population is distributed over space. The distributed population and threshold rules are subsequently used to simulate the conversion to urban and abandoned urban land uses before all other simulated land-use types are allocated in the discrete land-use allocation method. Following observed land-use and population distributions, pixels become urban if their modelled population exceeds 6 inhabitants; conversely, urban pixels become 'abandoned' when their modelled population declines below 2 inhabitants. The distribution of population is foremost based on a 'population potential' function that describes likely population counts per grid unit. This is a linear function incorporating neighbourhood interdependencies, the log-linear distance to the closest road, current potential accessibility, slope and current land uses; it is fitted on the observed 2006 population distribution by means of spatial econometric methods. For an overview of spatial econometric methods see Anselin [34]. Population allocation in LUISA is subsequently restricted by three factors. Regional urban land demands are accounted for, implying that minimum and maximum limits are imposed on the number of pixels that reach the urbanization threshold. Regional urban land demands are based on: 1) recent Europop 2010 population projections [35]; 2) an assumed Europe-wide convergence of average household sizes on the very long run (i.e., to 1.8 in all regions by 2100 , so that in most regions a limited decrease in household size is modelled by 2030); and 3) extrapolated historical trends of regional urban land consumption per household. In each time step the population distribution method allocates the net regional population growth in a region, as projected by Eurostat, as well as $10 \%$ of the pre-existing population in order to take internal movements into account. The $10 \%$ internally moving population is a coarse estimate of internal movements that is used because projected internal migration numbers are unavailable. Lastly, the method is restricted by per-pixel housing supply, which is approximated in terms of inhabitant capacity in the model and is instrumental in imposing a larger degree of inertia on the model results. Approximated housing supply increases potential population if current population undershoots population capacity, and it penalizes population potential if population counts are higher than housing supply. Every five time steps it assumes the values from current modelled population counts to proxy structural changes in housing supply. 
Fig. 1 Flow chart of the LUISA land-use model

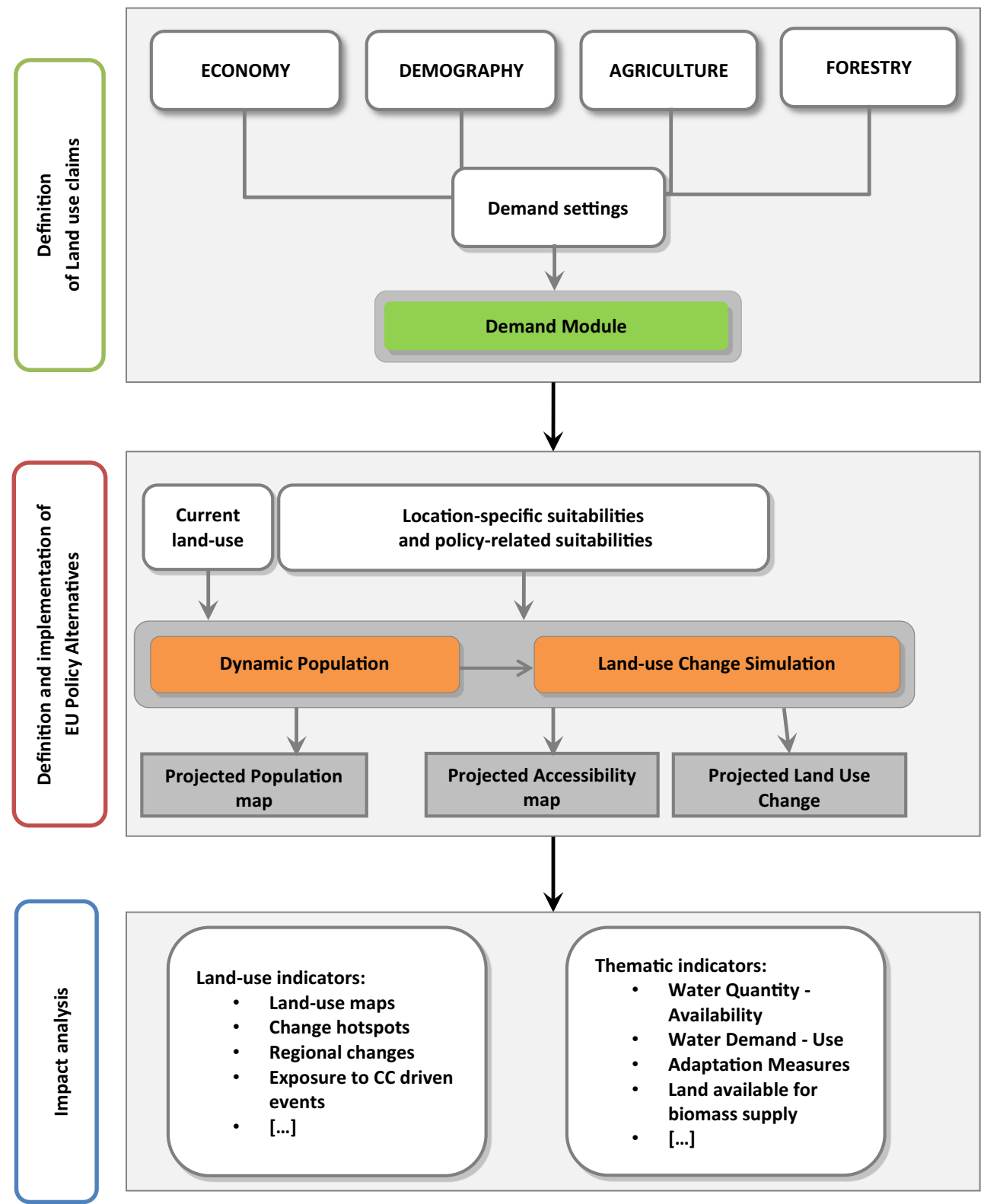

A second recent addition to LUISA is the inclusion of endogenous potential accessibility as a suitability factor for its land-use allocation and population distribution method. Here the model computes the following equation for each time step:

$A_{i}=\sum_{i=1}^{n} \frac{P_{j}}{f\left(c_{i j}+c_{j}\right)}$,

in which accessibility levels A for each origin point $i$ are computed using current population counts $P$ in destination zones $j$, the results of a function of traveltime $c$ between $i$ and $j$, and a zone-specific internal traveltime $c_{j}$. The origin points are equally distributed throughout Europe with roughly $15 \mathrm{~km}$ intervals. Within the model, the destination zones are hybrid sets that differ per modelled country and consist of municipalities within, and NUTS2 regions outside of the modelled countries. Although national borders impose substantial barriers on levels of spatial interaction and urban development near national borders [36-38], no penalties on potential cross-border interactions are currently imposed on accessibility values. Population counts are aggregated from the model's previous time step's population distribution outcomes in the modelled country. Regional Europop2010 population projections are used for the remaining regions. Traveltimes are obtained from the TRANS-TOOLS road network [39] using a shortest path algorithm assuming free-flow traveltimes. For the purpose of this study, current and future traveltimes are distinguished (see the following section). To account for the unknown distribution of 
destinations within zones an additional traveltime is added that essentially depends on a destination zone's geographical area. It uses the Frost and Spence [40] approach to approximate internal Euclidean distances; thus, internal distance $d_{j}$ is assumed to be $d_{j}=0.5 \sqrt{A R E A_{j} / \pi}$. Subsequently, internal travel times $c_{j}$ are computed from $d_{j}$ by means of a function in which effective travel speeds in $\mathrm{km} / \mathrm{h}$ are obtained with the fitted function $10.66+13.04 \ln \left(d_{j}\right)$, with a minimum of $5 \mathrm{~km} / \mathrm{h}$ imposed on very small zones (for details on the fitted function see [38]). Lastly the distance decay function $f\left(c_{i j}\right)$ in the model is of the form $c_{i j}{ }^{1.5}$. The form of the distance decay function was chosen among many tested in the population potential fitting exercise because, in terms of explained variance, it fitted best on observed population distributions.

The feedbacks between land-use and transport that are modelled in LUISA are characteristic of land-use/transport interaction models (LUTI). In LUISA, just as in most other LUTI [41], accessibility is used as an important factor in the location decisions that cause land-use change, and as an indicator of socio-economic welfare. For an overview of LUTI models we refer to Wegener [42]. Compared to other recently applied LUTI, for example MARS [18, 43] or TIGRIS XL [44], LUISA has a larger geographic extent (all of the European Union), operates at a finer resolution (the $100 \mathrm{~m}$ pixel level), takes into account a broader set of land uses (including agricultural and forest land uses), and reports on a much more diverse set of environmental and economic indicators (including for example accessibility and land-use efficiency, but also ecosystem services, freshwater consumption and energy provision). However, currently LUISA does not take into account some of the characteristic strongpoints of other LUTI such as the modelling of network use and congestion, the inclusion of multiple transport modes, and the incorporation of other human activities besides residence, such as employment. Future development plans for LUISA do include the estimation of transport network use and a further breakdown of human activity, if sufficiently detailed data becomes available on a Europe-wide scale. For the article at hand the model's shortcomings imply limitations to the breadth of the applied methods and drawn conclusions. Thus, for example the effects of transport investments that aim to alleviate congestion cannot be explored, and impacts related to job-market dynamics and job-market access cannot be presented.

\subsection{Modelling cohesion policy impacts}

LUISA allows multi-policy scenarios to be accommodated, so that several interacting and complementary dimensions of spatially relevant policies are represented. Often LUISA inherits policy provisions from other sector models. For example, the CAPRI model from which agricultural land demands are obtained takes the EU's Common Agricultural Policy on board, and the macro-economic models that project future industrial land demand pass through energy and economic policies $[45,46]$. Other policies such as nature protection schemes and transport infrastructure improvements are modelled in LUISA through assumed impacts on local suitability factors.

To assess the territorial consequences of EU cohesion policies, a number of impacts are inherited from upstream models; the most important example here is that the impacts of cohesion policy on industrial land demand were obtained
Fig. 2 Endogenous accessibility and population computations in LUISA

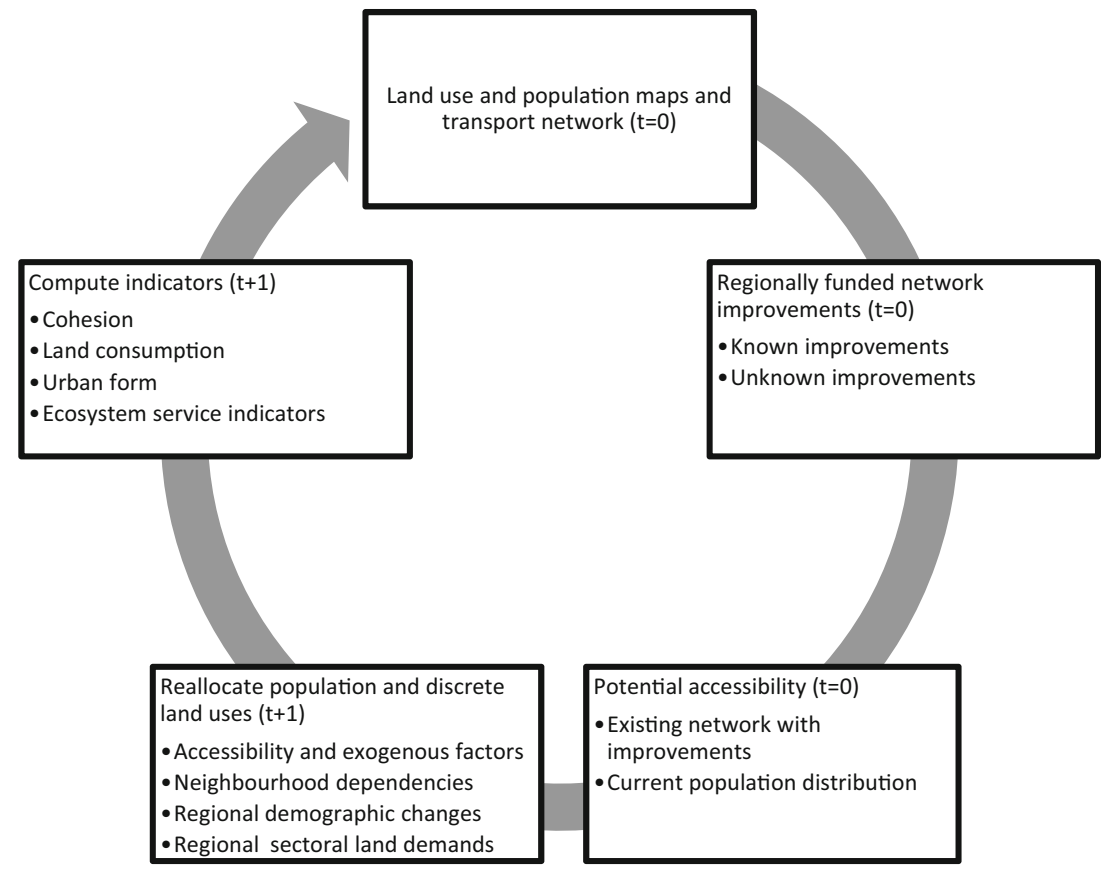


Table 1 Characteristics of road types as used in the upgrade funding allocation method and assumed amount of available funding

\begin{tabular}{lllll}
\hline Type of road & Assumed max. Speed & Number of lanes & Estimated cost per kilometre & $\begin{array}{l}\text { Cohesion policy investment categories } \\
\text { (assumed EU-wide funding) }\end{array}$ \\
\hline Local road & $80 \mathrm{~km} / \mathrm{h}$ & 2 & 3 M Euro & Regional and local roads (9.8 Bn) \\
National road & $100 \mathrm{~km} / \mathrm{h}$ & 2 & $4.2 \mathrm{M}$ Euro & National roads (7.7 Bn) \\
Motorway & $130 \mathrm{~km} / \mathrm{h}$ & 4 & 10 M Euro & Motorways (5.2 Bn) TEN motorways (17.5 Bn) \\
\hline
\end{tabular}

using forecasts of economic growth from the Rhomolo model [6]. Regional population projections were assumed not to change as a result of the cohesion policies. At the local level suitability factors were adapted in order to assess the impacts of cohesion policies on the spatial distribution of people and land uses. Only aspects of the cohesion policy with a clear impact on land-use patterns were taken into account: investments in transport networks, investments in urban regeneration, investment in research and technological development infrastructure, investment in social infrastructure and investments in improving existing ports and airports. In this article we elaborate on how road network improvements were modelled; for an overview of the other modelled cohesion policy impacts we refer to Batista e Silva et al. [22]. We will furthermore elaborate on the two contrasting urban development scenarios that were taken into account in the cohesion policy assessments.

\subsubsection{Taking into account road network funding}

The effects of future funding for motorways and local, regional and national roads have been modelled explicitly by taking into account future changes in traveltimes and their subsequent effects on potential accessibility. The way that road upgrades were incorporated in LUISA is shown schematically in Fig. 2. Because the true distribution of funding in the cohesion policy was not yet known at the time the research was conducted, the funds were assumed to be the same as in the 2007 to 2013 programme. Those funds are destined to three distinct road types, namely motorways, national roads and local roads. All modelled road network improvements were assumed to lead to traveltime improvements, either by new links identified in the used TRANS-TOOLS data, or by upgrades to the existing road network. The costs of upgrading one kilometre of lane were averaged from a European database of road construction projects that have successfully been implemented with cohesion policy funding; see EC [47]. For the purpose of this paper the total EU investments cited for those projects are divided by the length of the built road and the number of constructed lanes. Subsequently total road construction costs were estimated for the three road types based on an assumed amount of lanes per type. All cost assumptions are given in Table 1. We must acknowledge that the costs quoted here are very rough estimates that do not take into account terrain conditions, nationally varying pricing structures or complex civil engineering works. These estimates have nonetheless been used because more accurate information on road construction costs was unavailable. Finally, please note that the recorded projects are only co-funded by the EU so that only a part of the entire project costs are taken into account. The accounted partial costs are consistent with the modelling approach in which the effects of future EU subsidies on road network development are modelled.

Table 2 Accessibility measures used in this study and their definition

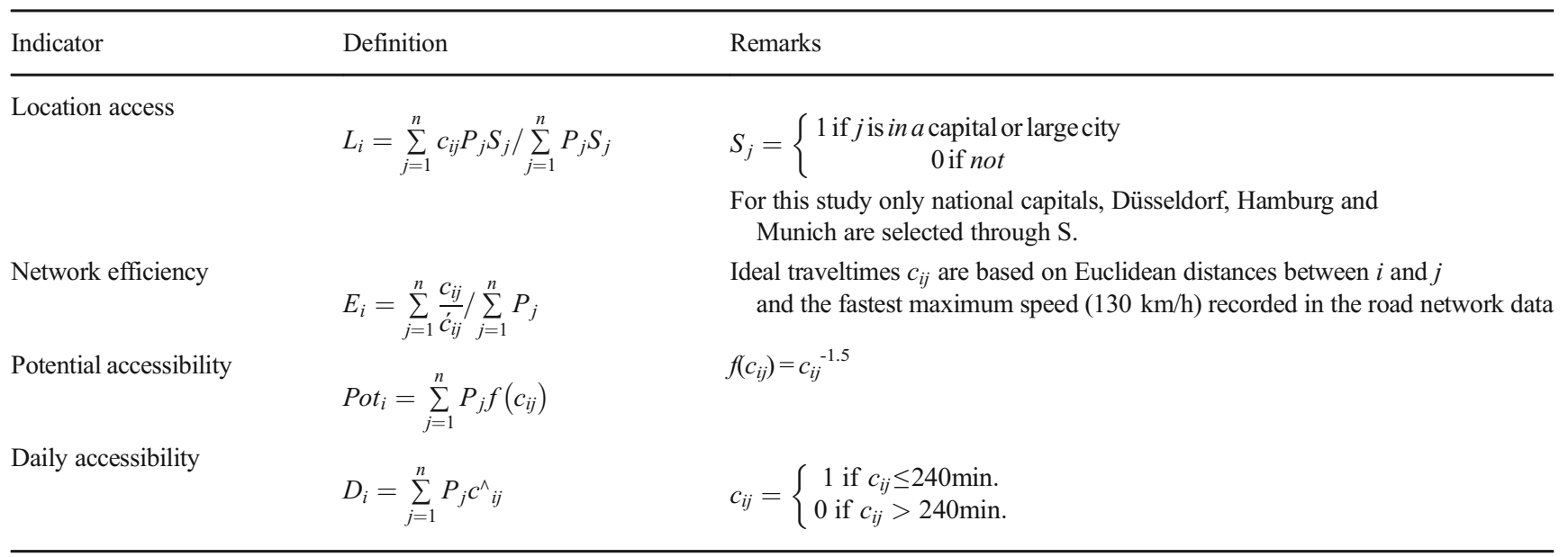


Table note: these are the costs for road projects incurred by the European Commission in projects that are only co-funded by the European Commission. Total construction costs may be much higher.

Given the costs of constructing a kilometre of a certain road type, the costs of road network improvements that are known a-priori were computed first. In many regions a substantial amount of funding was not depleted by those already known infrastructure developments. In such regions the remainder funding was allocated to road segments that, according to some simple rules, are likely candidates for upgrades. In that way all regional funding was allocated to road network improvements. The selected road segments had to meet the following criteria: they 1) were not known to be upgraded; 2) had slower recorded maximum speeds than typical for the destination road type; and 3) had the highest transport demand according to a simple transport modelling exercise. That transport modelling exercise is based on a straightforward spatial interaction model of the form $T_{i j}=P_{i} P_{j} c_{i j}{ }^{-2}$, with demand for flows $\mathrm{T}$ between municipalities $i$ and $j$, population counts $P$ and traveltimes $c$. The demands $\mathrm{T}$ were allocated to the shortest path between $i$ and $j$, yielding estimated flows per road segment. With the set criteria, first upgrades to motorway level were allocated, and subsequently upgrades to regional

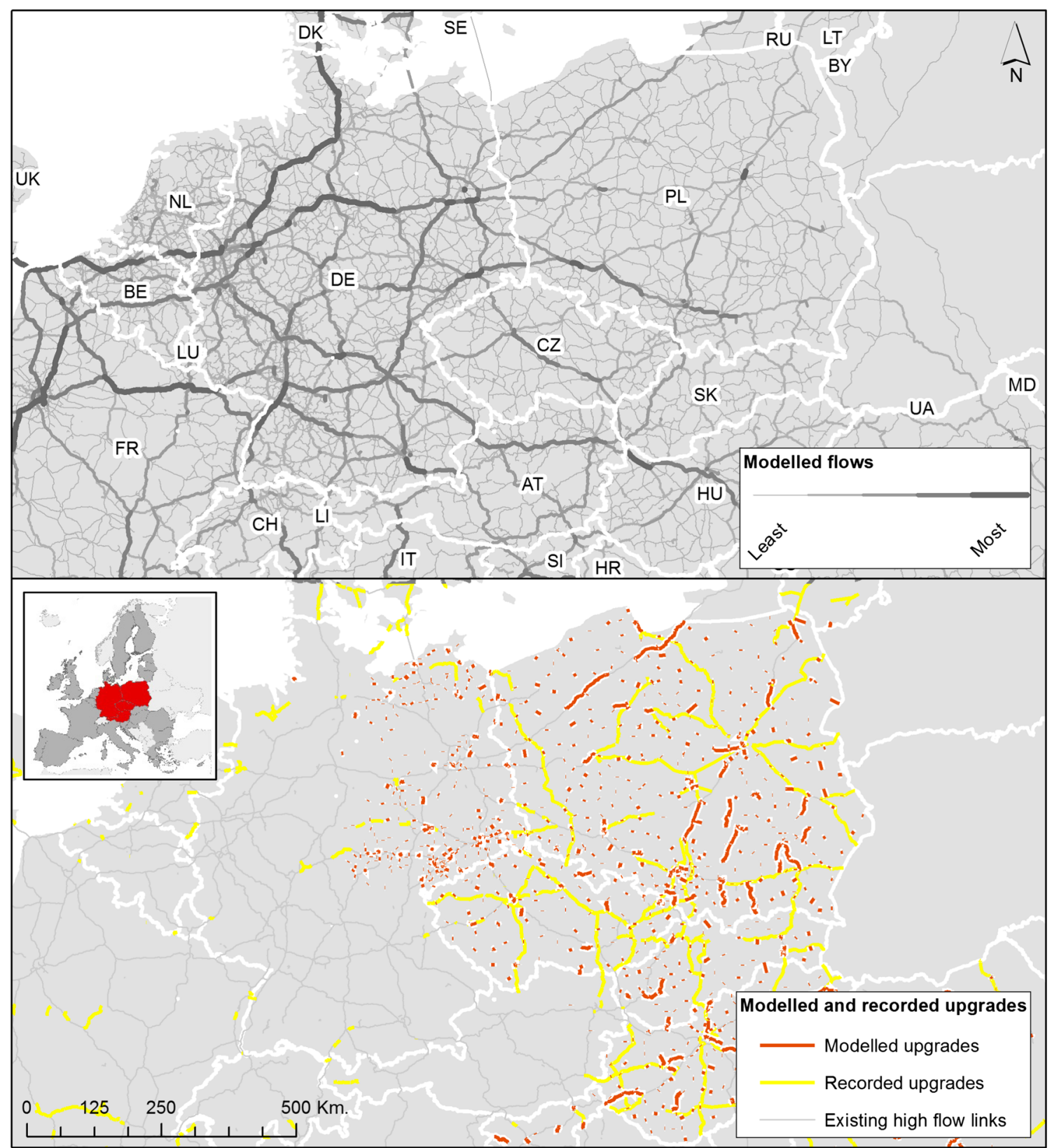

Fig. 3 Above: modelled flows using 2006 population and road network data. Below: the road upgrades that are assumed to be in place in 2030 that are based on the modelled flows 
Table 3 Inequality indicators of average road speeds in the historical network and in the network used for modelling

\begin{tabular}{|c|c|c|c|c|c|c|}
\hline \multirow[t]{2}{*}{ Regional speeds distribution } & \multirow[t]{2}{*}{ Network 1971 (r) } & \multicolumn{2}{|c|}{ Network 2012} & \multirow[t]{2}{*}{ Network 2006 (I) } & \multicolumn{2}{|c|}{$\begin{array}{l}\text { Network } 2030 \\
\text { (II - IV) }\end{array}$} \\
\hline & & & $\% \operatorname{dif}$ & & & $\%$ dif \\
\hline Coeff. of variation & 0.106 & 0.080 & -24.43 & 0.233 & 0.193 & -17.32 \\
\hline Gini index & 0.057 & 0.042 & -27.26 & 0.124 & 0.105 & -15.29 \\
\hline Theil (0) & 0.006 & 0.003 & -42.75 & 0.031 & 0.020 & -36.02 \\
\hline Atkinson $(0.5)$ & 0.003 & 0.002 & -42.70 & 0.017 & 0.011 & -39.01 \\
\hline
\end{tabular}

Note: case numbers (I to IV) are given between parentheses. Case $r$ serves as a reference for the relative differences in the historical trends; case I serves as a reference for the relative differences in the modelling results and local roads. This was done until no more road segments could be upgraded because funds were depleted or because no more segments that meet the criteria were available in a region. This method assumes that network investment decisions follow an ad-hoc rationale of catering for transport demand where this is needed the most. We believe this is a fair assumption as long as strategic network investment plans are unknown for the regions that receive funding. We must acknowledge that the used transport demand figures are obtained from a rather coarse method that for example does not take into account spatially varying car ownership or the lessening effects that national borders have on transport flows [48]. We expect that this method is nonetheless useful here to demonstrate the effects that potential infrastructure investments may have on accessibility levels. Finally, the network improvements were assumed to be completed by 2030 , with linearly improving traveltimes between 2006 and 2030 that fed into the LUISA accessibility computations.

\subsubsection{Two contrasting scenarios of urban development}

Unfortunately, local urban planning policies and regulations are not included in LUISA, even though their effect on future local land-use patterns is presumably profound. Such local policies are excluded because consistent Europe-wide data related to urban plans are yet unavailable. To sketch the potential impacts of cohesion policies with different local planning policies, those impacts have been computed with two contrasting, stylised spatial planning regimes. The choice of planning regimes reflects the contradiction between sprawled and compact urban development that is often addressed in spatial planning evaluation $[17,49]$. In the Compact scenario (case III), urban development is restricted to the immediate surroundings of existing urban areas, thus leading to densification and expansion of existing urban perimeters, while limiting scattered and uncontrolled development. Because of the restricted availability of land near urban areas, this scenario additionally yields a more evenly spread urban development within regions. In the BAU scenario of urban development (case IV), urban areas are allowed to develop freely, are attracted to the areas with the highest gravitational attraction, and there form relatively scattered patterns that generally follow the main transport axes.

\subsection{Measuring cohesion effects on accessibility}

To study the effects of transport network improvements on accessibility a number of accessibility measures need to be selected from the many accessibility measures that are available in the existing literature; see for example Geurs and Van Wee [1]. We used the same set of accessibility measures as López et al. [5]. These measures are location accessibility, relative network efficiency, potential accessibility and daily accessibility, which can be loosely linked to specific policy objectives: location accessibility measures the degree in which locations are linked [9]; network efficiency measures the effectiveness of transport networks [5]; potential accessibility measures economic opportunity $[5,8]$; and daily accessibility can perhaps indicate aspects of quality of life objectives, as it measures the opportunities that people may enjoy on a daily basis.

All accessibility indicators use shortest traveltimes $\left(c_{i j}\right)$ between $i$ and $j$ and population at the destination $\left(P_{j}\right)$. The list of used indicators is shown in Table 2 . In all cases, the regularly distributed points described in Section 2.1 were used as origins, and municipalities were used as destinations. The road network data used to obtain traveltimes describes the current (2006) road network in case I, and describes the expected future (2030) network in cases II to IV. The latter takes into account the expected network improvements enabled by cohesion policy funding. For municipal populations the current

Table 4 Population projections used in the population modelling exercise aggregated per country

\begin{tabular}{lrrr}
\hline Country & Population 2006 & Population 2030 & \% dif \\
\hline Austria & $8,254,298$ & $8,849,533$ & $7 \%$ \\
Czech Republic & $10,251,079$ & $10,839,979$ & $6 \%$ \\
Germany & $82,437,995$ & $77,871,677$ & $-6 \%$ \\
Poland & $38,157,055$ & $37,564,976$ & $-2 \%$ \\
Total & $139,100,427$ & $135,126,165$ & $-3 \%$ \\
\hline
\end{tabular}

Source: Europop2010 [35]. 


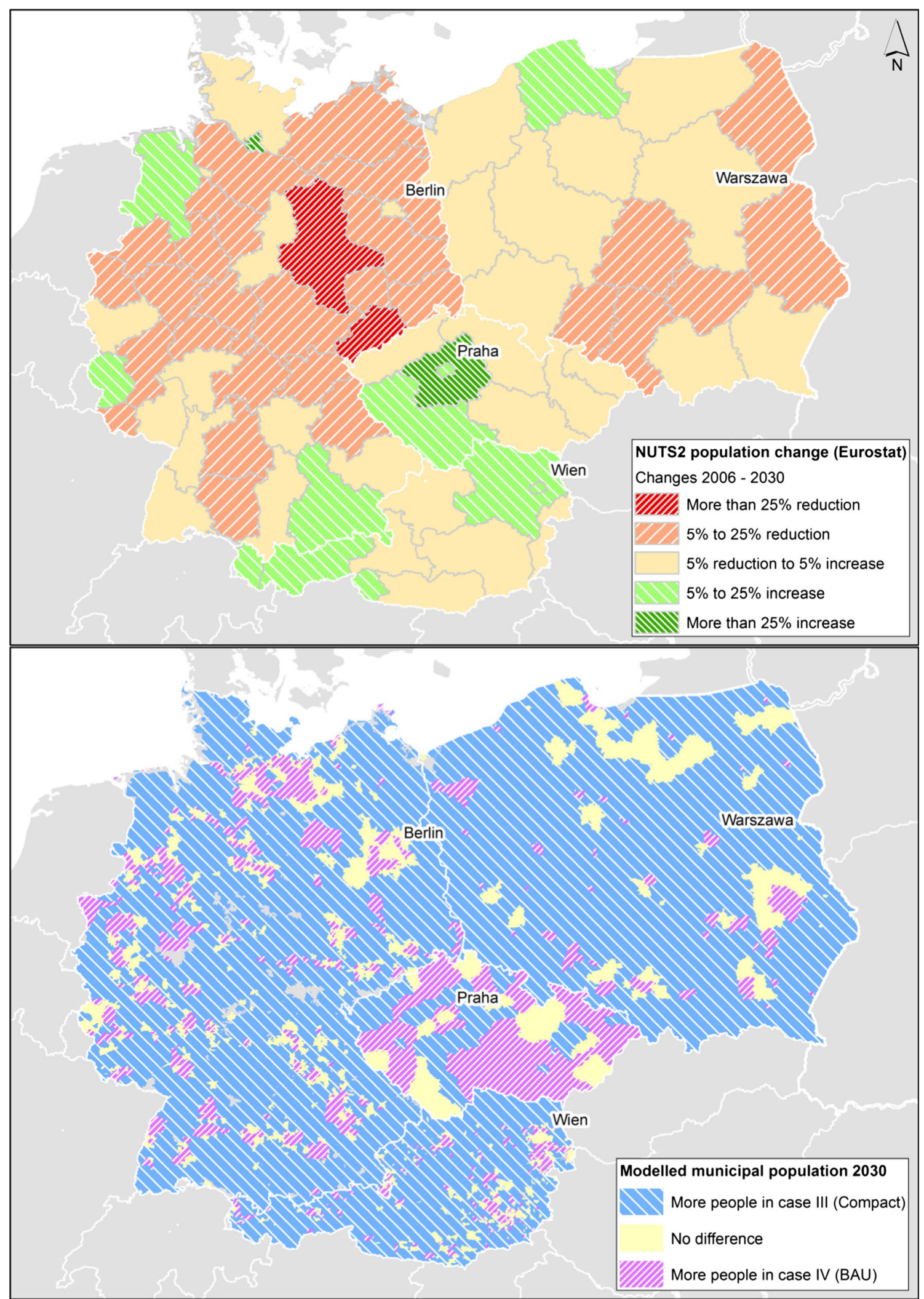

Fig. 4 Above: projected population changes per NUTS2 region from 2006 to 2030 [35] as modelled in cases III (Compact scenario) and IV (BAU scenario). Below: the differences in modelled municipal population between those two cases

(2006) population levels were used in cases I and II, while in cases III and IV future (2030) population levels modelled by
LUISA were applied. All accessibility measures were computed for the roughly 22,000 municipalities in the study area. We 
must acknowledge that the selected accessibility indicators do not provide a comprehensive overview of socially relevant accessibility effects. As Geurs [50] and Wang et al. [18] show, accessibility indicators that include competition effects at the destination may add relevant information considering access to resources with limited capacity, such as jobs or public facilities. Because such resources are not yet modelled in LUISA, competition effects cannot be taken into account in this exercise.

Subsequently, a number of indicators were computed that measure the territorial cohesion of the various accessibility indicators. The diversity indicators that have been proposed for measuring cohesion effects by López et al. [5] were used here. These indicators are the coefficient of variation and the Gini, Atkinson and Theil indices. All indicators capture the degree to which endowments are inequally distributed over areal units, but differ in the emphasis put on the distribution of high and low values. In all cases, lower values of the indicator signify greater equality of endowments and thus increased territorial cohesion.

\subsection{Historical data for reference}

To provide some reference to the modelling results, the same set of variables and indicators will be computed using historical data that has very recently become available. One used data-source describes municipal population counts in 1971 and 2011 in all municipalities in the selected countries [51]. The other used data describe the European road network in 1970 and 2012 [52] in a level of detail that is roughly comparable with the TRANS-TOOLS data used in the LUISA modelling effort. Thus, for the sake of comparison, historical trends regarding the cohesion effects of population and network changes are computed in the four selected countries.

\section{Results}

In this section, first the results of allocating available funding to currently unknown future network improvements will be demonstrated along with the modelled population changes.
Subsequently potential impacts of the cohesion policy on population distribution and accessibility levels will be discussed. Results from 2006 will be compared with results from 2030. Results from 1971 to 2011 are used to provide an historical reference. Please note that, because of the assumed linearly changing traveltime improvements, the impacts of intermediate years will fall roughly between the 2006 and 2030 results.

\subsection{Allocated infrastructure improvements and population changes}

According to the available data, roughly $16.000 \mathrm{~km}$ of road are known to be upgraded or constructed as motorways with cohesion policy funding. Not all funding is depleted with those upgrades. The previously outlined upgrade allocation method yields that an additional $700 \mathrm{~km}$ of road in Europe are upgraded to motorways. This method furthermore yields that $3600 \mathrm{~km}$ of road are upgraded to national roads and $6500 \mathrm{~km}$ of local roads are upgraded to the maximum speeds of the local/regional road level. The transport modelling results and the distribution of new links is shown in Fig. 3. From the assumed funding distribution follows that new EU member states such as Poland and Czech Republic will receive the most substantial funding for upgrades to the road network. This result is not surprising, given the speed at which road networks are expanding in the EU's new member states [8].

To understand how the modelling network compares with historical road data, road speeds for 1971 and 2012 (historical network) as well as for 2006 and 2030 (modelling network) have been averaged for all European regions. Those averages are weighted by segment length so that longer links have a greater weight in the network average. When comparing average regional speeds, the historical network and the modelling network are considerably different. In the modelling network, regional inequalities are much more profound even when compared to the 1971 network; see Table 3. Thus the modelling network potentially overestimates disparities in accessibility. By 2030, speeds on Europe's road networks are expected to be more equally distributed. However, the modelled pace of inequality reduction does not keep up with historical trends. This is no doubt because only EU-funded
Table 5 Inequality indicators of observed population distributions in 1971 and 2011, and in 2006 and 2030 according to the LUISA's Compact and BAU scenarios

\begin{tabular}{|c|c|c|c|c|c|c|c|c|}
\hline \multirow[t]{2}{*}{$\begin{array}{l}\text { Population } \\
\text { distribution }\end{array}$} & \multirow[t]{2}{*}{$\begin{array}{l}\text { Population } \\
1971(r)\end{array}$} & \multicolumn{2}{|c|}{$\begin{array}{l}\text { Population } \\
2011\end{array}$} & \multirow{2}{*}{$\begin{array}{l}\text { Population } \\
2006 \\
\text { (I and II) }\end{array}$} & \multicolumn{2}{|c|}{$\begin{array}{l}\text { Compact } \\
\text { scenario (III) }\end{array}$} & \multicolumn{2}{|c|}{$\begin{array}{l}\text { BAU scenario } \\
\text { (IV) }\end{array}$} \\
\hline & & & $\%$ dif & & & $\%$ dif & & $\% \operatorname{dif}$ \\
\hline Variation coeff. & 6.695 & 6.482 & -3.17 & 6.355 & 8.334 & 31.13 & 9.462 & 48.89 \\
\hline Gini index & 0.778 & 0.783 & 0.54 & 0.782 & 0.858 & 9.72 & 0.883 & 12.83 \\
\hline Atkinson (0.5) & 0.536 & 0.541 & 0.89 & 0.541 & 0.668 & 23.51 & 0.711 & 31.59 \\
\hline Theil (0) & 1.775 & 1.743 & -1.81 & 1.733 & 2.354 & 35.83 & 2.658 & 53.35 \\
\hline
\end{tabular}

Note: case numbers (I to IV) are given between parentheses. Case $r$ serves as a reference for the relative differences in the historical trends; case I serves as a reference for the relative differences in the modelling results 
network upgrades are foreseen in this analysis, so that many future network upgrades are likely not accounted for. To tackle that potential hiatus in knowledge, an effort to comprehensively project road network improvements in the EU is necessary, but such an exercise is outside the scope of this paper.
Next to infrastructure improvements, population changes affect the analysed accessibility levels. In this modelling exercise, all future population levels are based on the 'Europop2010' regional population projections for 2030. Those projections assume a general $7 \%$ population growth

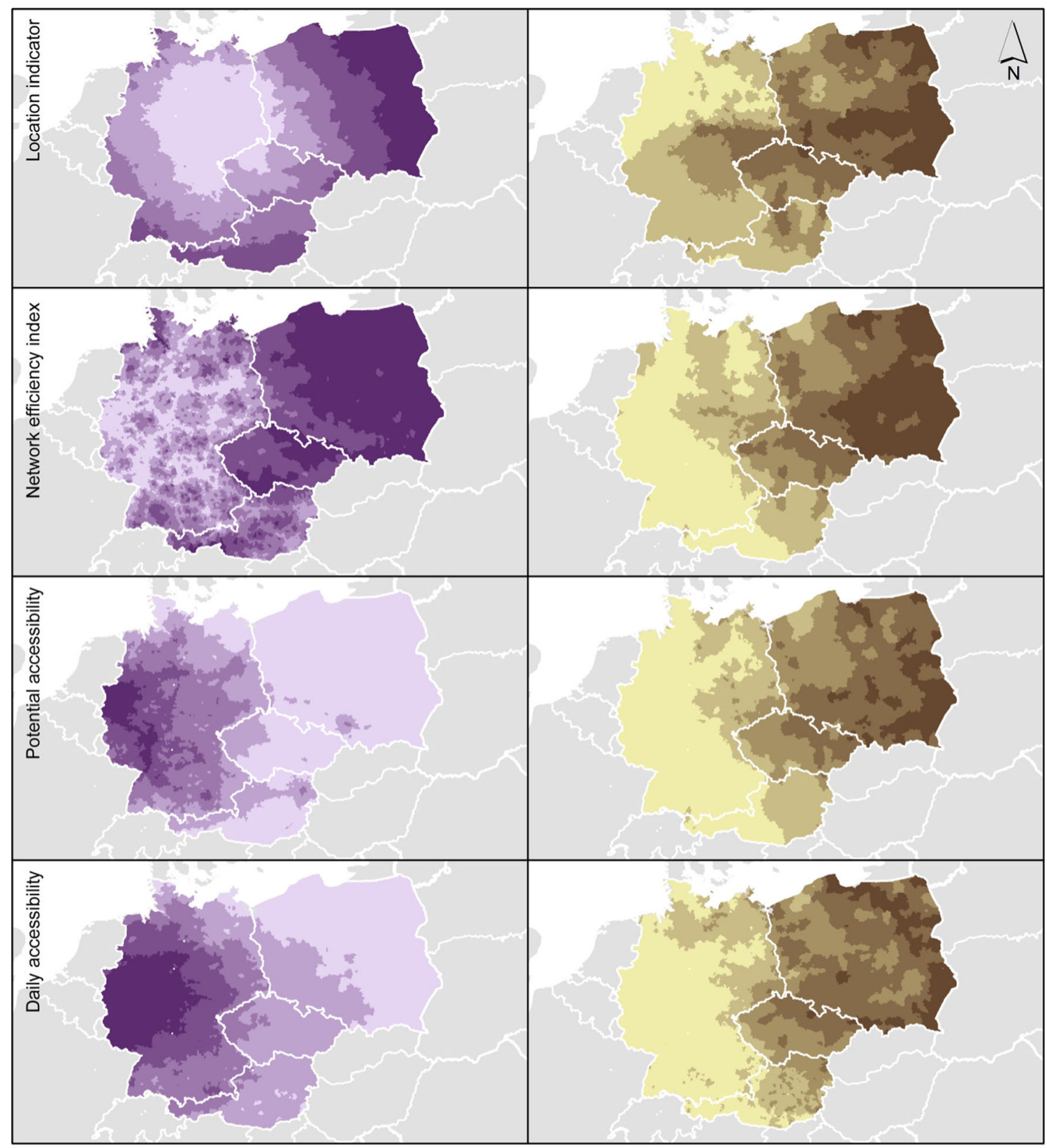

Accessibility levels in 2006 (Case I)

Network 2006 and population 2006

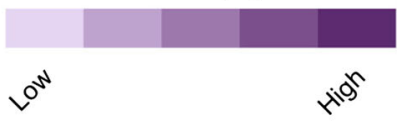

Fig. 5 Left: spatial distribution of accessibility levels with 2006 data (case I). Right: improvements in accessibility levels when taking only network changes into account (case II). The class breaks represent a
Improvement in accessibility levels (Case II)

Network 2030 and population 2006

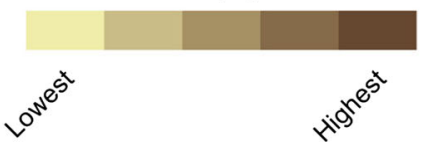

Jenk's natural break distribution. Cases III and IV are deliberately excluded here to save space; when mapped the changes brought forth by those cases appear very similar to the results of case II 
in all of Europe between 2006 and 2030, but a 3 \% population decrease in the study area (see Table 4).

In Fig. 4 the projected regional population changes are shown as well as the differences in the municipal population distribution as modelled by LUISA in the Compact and BAU scenarios. In both scenarios, regional migration flows modelled in the Europop2010 population projections cause that population levels will have increasingly inequal distributions in the study area. In fact, a quick check shows that the Europop2010 projections cause a $3 \%$ to $5 \%$ increase in population concentration. At the local level the modelled level of population concentration is even more pronounced, with up to $53 \%$ increases in population inequality indicators.

When comparing the results from modelled population distributions with historical trends, it is immediately clear that the concentration tendencies in the modelling results are more conspicuous than in the historical trends. This can to some degree be explained by the increased concentration according to the used Europop2010 projections. Nevertheless, although we must repeat here that past trends are not indicative of future changes, the contradictory results may still signal a bias in the modelling results towards more concentrated population distributions. To verify the validity of modelling results, the team involved in developing the LUISA model is therefore using historical population data to explore whether variables that are relevant for population distributions are missing in the current approach. Notwithstanding whether the future will resemble the modelled trends, useful information can be extracted from a comparison of the modelled scenarios of land-use developments. Table 5 shows that in case III the regional inequality of population levels is much less compared with case IV. As Fig. 4 shows, in case III urban development is less substantial in the environs of the largest urban areas; this is due to the more restricted supply of land there in that scenario. Instead, in that case urban development is more evenly distributed near the edges of the various smaller and larger urban areas within the modelled regions. Thus, within the frame of overall population trends, the level of land-use development can have a substantial impact on population distribution outcomes.

\subsection{Territorial cohesion impacts of accessibility}

We proceed to discuss the territorial cohesion effects of the modelled accessibility changes. Here we take into account accessibility levels with the reference 2006 population and network (case I); with the 2006 populations but with network improvements in place (case II), so that the separate effects of infrastructure improvements and population changes can be observed; and lastly with 2030 population levels according to the Compact and BAU scenarios of local urban development (respectively cases III and IV). Reference accessibility levels and the relative effect of the assumed road network
Table 6 Averaged accessibility levels per country given current and expected future road networks and the Compact and BAU scenarios of population change

\begin{tabular}{|c|c|c|c|c|c|c|c|}
\hline \multirow{2}{*}{$\begin{array}{l}\text { Network } \\
\text { Population }\end{array}$} & \multirow{2}{*}{$\begin{array}{l}2006 \\
2006(\mathrm{I})\end{array}$} & \multicolumn{6}{|l|}{2030} \\
\hline & & \multirow[t]{2}{*}{2006 (II) } & & \multicolumn{2}{|c|}{ Compact scenario (III) } & \multicolumn{2}{|c|}{ BAU scenario (IV) } \\
\hline Austria & & & $\%$ dif & & $\% \operatorname{dif}$ & & $\%$ dif \\
\hline Location & 352 & 345 & -1.99 & 352 & -0.11 & 354 & 0.35 \\
\hline Network efficiency & 1.50 & 1.47 & -1.94 & 1.47 & -2.14 & 1.47 & -2.20 \\
\hline Potential & 59,199 & 60,431 & 2.08 & 63,187 & 6.74 & 63,184 & 6.73 \\
\hline Daily & 43.79 & 45.64 & 4.23 & 47.78 & 9.11 & 47.76 & 9.07 \\
\hline \multicolumn{8}{|l|}{ Czech Rep. } \\
\hline Location & 295 & 285 & -3.41 & 298 & 0.95 & 303 & 2.63 \\
\hline Network efficiency & 1.56 & 1.51 & -3.27 & 1.50 & -3.73 & 1.50 & -3.80 \\
\hline Potential & 57,380 & 60,674 & 5.74 & 62,571 & 9.05 & 62,573 & 9.05 \\
\hline Daily & 43.50 & 48.42 & 11.30 & 48.32 & 11.07 & 48.44 & 11.35 \\
\hline \multicolumn{8}{|l|}{ Germany } \\
\hline Location & 273 & 269 & -1.62 & 268 & -1.80 & 272 & -0.52 \\
\hline Network efficiency & 1.47 & 1.44 & -1.81 & 1.44 & -2.03 & 1.43 & -2.10 \\
\hline Potential & 81,560 & 82,702 & 1.40 & 84,733 & 3.89 & 85,316 & 4.60 \\
\hline Daily & 71.99 & 73.21 & 1.70 & 72.68 & 0.97 & 73.12 & 1.58 \\
\hline \multicolumn{8}{|l|}{ Poland } \\
\hline Location & 404 & 384 & -4.98 & 396 & -1.85 & 399 & -1.29 \\
\hline Network efficiency & 1.60 & 1.52 & -4.55 & 1.52 & -4.96 & 1.52 & -5.02 \\
\hline Potential & 42,215 & 45,736 & 8.34 & 46,853 & 10.99 & 47,265 & 11.96 \\
\hline Daily & 25.75 & 29.74 & 15.47 & 29.56 & 14.77 & 29.81 & 15.77 \\
\hline
\end{tabular}

Note: all relative differences are computed with case I as reference. Case numbers (I to IV) are given between parentheses 
improvements on accessibility measures are plotted in Fig. 5. For all scenarios the averaged accessibility changes per country are furthermore given in Table 6 . In both the mentioned figure and table, population levels are held static. The results show that, in relative terms, the assumed road network improvements have a profound effect on accessibility levels in particular in the easternmost regions of Poland and Czech Republic. In contrast, western Germany is hardly affected by the EU funded infrastructure improvements. These results confirm that EU road investments are the largest in more peripheral regions $[8,9]$. Nevertheless, the infrastructure improvements do not affect the ranking of countries in terms of accessibility levels, and in absolute terms, the changes are modest. That the absolute accessibility effects of the infrastructure investments are so modest is without doubt caused by the fact that accessibility levels in the studied countries were already reasonably high in 2006.

The redistribution of population as modelled in LUISA substantially impacts accessibility levels. In general, the change in the location indicator is much smaller with future population levels, network efficiency is slightly increased and potential accessibility is much larger; while the effects on daily accessibility are mixed. The significant increase in potential accessibility in Germany, despite the overall population decline, is surprising. The observed increase of potential accessibility occurs in both cases III and IV and must therefore be due to regional population trends. This shows that such regional population distributions can have a substantial impact on potential accessibility levels. While cases III and IV yield consistently better average accessibility levels than the scenarios that ignore population changes (I and II), the results of cases III and IV do not differ much between themselves. This shows that, when considering average accessibility levels, regional population projections surely matter, but the aggregate effect of differing local urbanization patterns is rather limited.

In contrast to average accessibility levels, territorial cohesion indicators can change considerably with different local urbanization patterns. Table 7 shows cohesion effects of the outcomes of accessibility indicators in cases I to IV. Comparing cohesion indicators when only the network improvements are in place yields that the infrastructure improvements considerably increase cohesion: here, in all cases the inequality indices are lower when the 2030 network is taken into account. This is consistent with the findings of López et al. [5]. However, when projected population changes are

Table 7 Inequality indicators of accessibility levels given current and expected future road networks and the Compact and BAU scenarios of population change

\begin{tabular}{|c|c|c|c|c|c|c|c|c|c|c|c|c|}
\hline \multirow{2}{*}{$\begin{array}{l}\text { Data source } \\
\text { Network }\end{array}$} & \multicolumn{5}{|l|}{ Observed } & \multicolumn{7}{|l|}{ Modelled } \\
\hline & 1970 & 2012 & & & & 2006 & 2030 & & & & & \\
\hline Population & $1971(r)$ & 1971 & & 2011 & & 2006 (I) & 2006 (II & & Comp & nario (III) & BAU s & ario (IV) \\
\hline Coefficient of variation & & & $\% \operatorname{dif}$ & & $\%$ dif & & & $\%$ dif & & $\%$ dif & & $\%$ dif \\
\hline Location & 0.074 & 0.046 & -37.6 & 0.041 & -44.0 & 0.191 & 0.182 & -4.5 & 0.184 & -3.5 & 0.179 & -6.2 \\
\hline Network efficiency & 0.143 & 0.051 & -64.2 & 0.052 & -63.4 & 0.041 & 0.033 & -18.7 & 0.033 & -20.7 & 0.033 & -20.7 \\
\hline Potential & 0.432 & 0.332 & -23.2 & 0.336 & -22.3 & 0.285 & 0.266 & -6.7 & 0.269 & -5.8 & 0.273 & -4.3 \\
\hline Daily & 0.596 & 0.423 & -29.0 & 0.426 & -28.5 & 0.430 & 0.391 & -9.1 & 0.393 & -8.7 & 0.394 & -8.4 \\
\hline \multicolumn{13}{|l|}{ Gini index } \\
\hline Location & 0.042 & 0.026 & -38.2 & 0.023 & -44.5 & 0.099 & 0.097 & -2.4 & 0.097 & -2.1 & 0.094 & -4.8 \\
\hline Network efficiency & 0.066 & 0.025 & -62.2 & 0.025 & -61.7 & 0.023 & 0.019 & -19.3 & 0.018 & -21.4 & 0.018 & -21.4 \\
\hline Potential & 0.235 & 0.181 & -22.9 & 0.183 & -22.1 & 0.158 & 0.147 & -7.0 & 0.148 & -6.7 & 0.149 & -5.5 \\
\hline Daily & 0.325 & 0.237 & -27.0 & 0.236 & -27.4 & 0.240 & 0.219 & -9.0 & 0.219 & -8.9 & 0.220 & -8.6 \\
\hline \multicolumn{13}{|l|}{ Theil (0) } \\
\hline Location & 0.003 & 0.001 & -62.0 & 0.001 & -69.3 & 0.017 & 0.016 & -7.4 & 0.016 & -6.1 & 0.015 & -11.3 \\
\hline Network efficiency & 0.009 & 0.001 & -86.2 & 0.001 & -85.6 & 0.001 & 0.001 & -33.9 & 0.001 & -37.1 & 0.001 & -37.2 \\
\hline Potential & 0.091 & 0.055 & -39.9 & 0.055 & -39.1 & 0.040 & 0.035 & -13.1 & 0.035 & -11.8 & 0.036 & -9.5 \\
\hline Daily & 0.168 & 0.089 & -46.8 & 0.089 & -47.1 & 0.092 & 0.076 & -17.0 & 0.076 & -16.6 & 0.077 & -16.2 \\
\hline \multicolumn{13}{|l|}{ Atkinson (0.5) } \\
\hline Location & 0.001 & 0.001 & -62.4 & 0.000 & -69.7 & 0.008 & 0.008 & -6.8 & 0.008 & -5.9 & 0.007 & -11.0 \\
\hline Network efficiency & 0.004 & 0.001 & -85.7 & 0.001 & -85.2 & 0.000 & 0.000 & -33.9 & 0.000 & -37.1 & 0.000 & -37.1 \\
\hline Potential & 0.046 & 0.028 & -40.1 & 0.028 & -39.5 & 0.020 & 0.017 & -13.2 & 0.017 & -12.1 & 0.018 & -9.9 \\
\hline Daily & 0.084 & 0.046 & -45.8 & 0.045 & -46.8 & 0.046 & 0.039 & -17.0 & 0.039 & -16.7 & 0.039 & -16.4 \\
\hline
\end{tabular}

Note: all relative differences in the observed data are computed with case $r$ as reference; all relative differences in the modelled data are computed with case I as reference. Case numbers (I to IV) are given between parentheses 
taken into account, the cohesion impacts of infrastructure improvements are much smaller. With most inequality indicators, potential and daily accessibility have a smaller but still positive impact on cohesion. Only the cohesion effects of network efficiency seem to consistently improve with the modelled population changes, while in particular the cohesion effects of potential accessibility levels suffer from the modelled population changes. Differences in local urban development patterns have a substantial impact on the used cohesion indicators, with differences in cohesion indicator values of over $20 \%$ in the case of potential accessibility. Comparing the results between cases III and IV, we find that more compact urban development decreases disparities in potential and daily accessibility, but increases disparities in location accessibility. Location accessibility, in fact, seems to profit considerably from the urban patterns modelled in the BAU scenario (case III).

All in all, cohesion indicators of accessibility are very sensitive for local population levels. This is again emphasized when looking at the results from historical data. Those data show much more profound impacts on cohesion indicators, which is no doubt caused by the substantial network improvements observed between 1970 and 2012 and the relatively small changes in inequality of population distributions. All in all, the historical data show a remarkable decline in accessibility disparities that are in many cases even augmented by changes in population distributions over time. Thus, from the historical trends and the modelled results we extract that investments in the road network may have a considerable impact on disparities in accessibility levels, and that land-use development policies may be used to restrict the potentially unwanted effects of population distributions on those disparities.

\section{Conclusions}

This article explores the cohesion effects of accessibility changes induced by road infrastructure upgrades, given ongoing population changes. Accessibility levels have been obtained using partially provisional road network improvements and future population distributions that are modelled on a fine spatial resolution. The aforementioned population distributions have been modelled to readjust to intermediately changing accessibility levels, regional demographic trends and various other factors. Two scenarios of urban development have been assessed here: a Business-As-Usual scenario with unrestricted urbanization patterns and, as a consequence, considerable relocation to each region's prime centres of attraction; and a Compact scenario with more restricted urbanization patterns, and ultimately more evenly spread population growth in a region. The used methods to model future population projections and their accessibility impacts provide a useful first insight into potential future outcomes. It is however important to note that the presented framework only supports the evaluation of general accessibility impacts and may be unable to evaluate specific aims of network investments. For example, accessibility impacts may differ across population groups with diverging activity patterns and transport mode availability [53], and network investments may be necessary to improve access to specific activity places (such as hospitals or schools) or to support large recurrent transport flows (for example for tourism or international commuting). A comparison with results from observed historical changes in population levels and the road network show that the LUISA model seems to overestimate the level of concentration in future population levels. This emphasizes the importance of empirical model validation exercises that are currently underway.

Some more general findings can be extracted from the found results by comparing accessibility results with different population distribution assumptions. Average accessibility levels are improved substantially by population changes in both cases that take future population projections into account. This shows that average accessibility levels depend substantially on future regional population levels. The effect of local population distributions on average national accessibility levels is fairly limited. However, variance in local urbanization patterns can have a drastic effect on the impact that infrastructural investments have on territorial cohesion; in some cases migration to main urban areas can substantially alter the decrease in disparities that infrastructure investments aim at. The results further show that the cohesion effects of transport network investments, such as for example reported by López et al. [5] and Stępniak and Rosik [8], can differ substantially when population changes are taken into account. All in all, if policy makers aim at reducing disparities between regions by means of infrastructure investments, they will do well to take future urbanization patterns and spatial planning policies into account when evaluating their plans. This may be necessary to ensure that network investments are effective and robust to possible population changes.

We cannot easily discern a good and a bad scenario of urban growth here, even when the only goal would be to preserve or increase territorial cohesion. Some accessibility measures yield better territorial cohesion in one scenario of urban growth, while other measures score better cohesion marks in the other scenario. The essential question here is which sort of accessibility needs to be optimized? If the emphasis is on more evenly spread economic opportunity, cohesion results of potential accessibility indicate that policies that incite more evenly spread urban development over different cities in a region have better cohesion effects. However, the effectiveness of such policies and the net welfare effects of inciting such urban development is unclear; furthermore, infrastructure developments may aim at optimizing very different accessibility measures. 
Open Access This article is distributed under the terms of the Creative Commons Attribution 4.0 International License (http:// creativecommons.org/licenses/by/4.0/), which permits unrestricted use, distribution, and reproduction in any medium, provided you give appropriate credit to the original author(s) and the source, provide a link to the Creative Commons license, and indicate if changes were made.

\section{References}

1. Geurs KT, Van Wee B (2004) Accessibility evaluation of land-use and transport strategies: Review and research directions. J Transp Geogr 12(2):127-140

2. Halden D (2002) Using accessibility measures to integrate land use and transport policy in Edinburgh and the Lothians. Transp Policy 9(4):313-324

3. Bertolini L, Le Clercq F, Kapoen L (2005) Sustainable accessibility: A conceptual framework to integrate transport and land use planmaking. Two test-applications in the Netherlands and a reflection on the way forward. Transp Policy 12:207-220

4. EC (2004) A new partnership for cohesion: Convergence competitiveness cooperation. Third report on economic and social cohesion. Publications Office of the European Union, Luxembourg

5. López E, Gutiérrez J, Gómez G (2008) Measuring regional cohesion effects of large-scale transport infrastructure investments: An accessibility approach. Eur Plan Stud 16(2):277-301

6. Brandsma A, Di Comite F, Diukanova O, Kancs A, Lopez Rodriguez J, Martinez Lopez D, Persyn D, Potters L (2013) Assessing policy options for the EU Cohesion Policy 2014-2020. Joint Research Centre of the European Commission

7. Martin JC, Gutiérrez J, Román C (2004) Data envelopment analysis (DEA) index to measure the accessibility impacts of new infrastructure investments: The case of the high-speed train corridor MadridBarcelona-French border. Reg Stud 38(6):697-712

8. Stęniak M, Rosik P (2013) Accessibility improvement, territorial cohesion and spillovers: A multidimensional evaluation of two motorway sections in Poland. J Transp Geogr 31:154-163

9. Gutiérrez J, Urbano P (1996) Accessibility in the European Union: The impact of the trans-European road network. J Transp Geogr 4(1):15-25

10. Xie F, Levinson D (2010) How streetcars shaped suburbanization: a Granger causality analysis of land use and transit in the Twin Cities. J Econ Geogr 10:453-470

11. Levinson D (2008) Density and dispersion: the co-development of land use and rail in London. J Econ Geogr 8:55-77

12. Koopmans C, Rietveld P, Huijg A (2012) An accessibility approach to railways and municipal population growth, 1840-1930. J Transp Geogr 25:98-104

13. Hansen WG (1959) How accessibility shapes land use. Journal of the American Institute of Planners 25:73-76

14. Meijers E, Hoekstra J, Leijten M, Louw E, Spaans M (2012) Connecting the periphery: Distributive effects of new infrastructure. J Transp Geogr 22:187-198

15. Padeiro M (2013) Transport infrastructures and employment growht in the Paris metropolitan margins. J Transp Geogr 31:44-53

16. Condeço-Melhorado A, Tillema T, De Jong T, Koopal R (2014) Distributive effects of new highway infrastructure in the Netherlands: the role of network effects and spatial spillovers. J Transp Geogr 34:96-105

17. Geurs K, Van Wee B (2006) Ex-post evaluation of thirty years of compact urban development in the Netherlands. Urban Stud 43(1): 139-160

18. Wang Y, Monzon A, Di Ciommo F (2014) Assessing the accessibility impact of transport policy by a land-use and transport interaction model - The case of Madrid. Comput Environ Urban Syst 49:126-135

19. Geurs KT, De Bok M, Zondag B (2012) Accessibility benefits of integrated land use and public transport policy plans in the Netherlands. In: Geurs KT, Krizek KJ, Reggiani A (eds) Accessibility analysis and transport planning. Edward Elgar, Cheltenham, pp. 135-153

20. Geurs KT, Van Wee B, Rietveld P (2006) Accessibility appraisal of integrated land-use - transport strategies: Methodology and case study for the Netherlands Randstad area. Environment and Planning B 33(5):639-660

21. Dekkers JEC, Koomen E (2007) Land-use simulation for water management: application of the Land Use Scanner model in two large-scale scenario-studies. In: Koomen E, Stillwell J, Bakema A, Scholten HJ (eds) Modelling land-use change; progress and applications. Springer, Dordrecht, pp. 355-373

22. Batista e Silva F, Lavalle C, Jacobs-Crisioni C, Barranco R, Zulian G, Maes J, Baranzelli C, Perpiña C, Vandecasteele I, Ustaoglu E, Barbosa A, Mubareka S (2013) Direct and indirect land use impacts of the EU cohesion policy.assessment with the Land Use Modelling Platform. Publications office of the European Union, Luxembourg

23. Lavalle C, Baranzelli C, Batista e Silva F, Mubareka S, Rocha Gomes C, Koomen E, Hilferink M (2011) A High Resolution Land use/cover Modelling Framework for Europe: introducing the EU-ClueScanner100 model. In: Murgante B, Gervasi O, Iglesias A, Taniar D, BO A (eds) Computational Science and Its Applications - ICCSA 2011, Part I, Lecture Notes in Computer Science, vol 6782. Springer-Verlag, Berlin, pp. 60-75

24. Hilferink M, Rietveld P (1999) Land Use Scanner: An integrated GIS based model for long term projections of land use in urban and rural areas. J Geogr Syst 1(2):155-177

25. Koomen E, Hilferink M, Borsboom-van Beurden J (2011) Introducing Land Use Scanner. In: Koomen E, Borsboom-van Beurden $\mathrm{J}$ (eds) Land-use modeling in planning practice. Springer, Dordrecht, pp. 3-21

26. Veldkamp A, Fresco LO (1996) CLUE: a conceptual model to study the Conversion of Land Use and its Effects. Ecol Model 85: 253-270

27. Verburg PH, Rounsevell MDA, Veldkamp A (2006) Scenario-based studies of future land use in Europe. Agric Ecosyst Environ 114(1):1-6

28. Verburg PH, Overmars K (2009) Combining top-down and bottomup dynamics in land use modeling: exploring the future of abandoned farmlands in Europe with the Dyna-CLUE model. Landsc Ecol 24(1167):1181. doi:10.1007/s10980-009-9355-7

29. ObjectVision (2014) Geo data and model server (GeoDMS). http:// objectvision.nl/geodms. Accessed 03/10/2014

30. Büttner G, Feranec J, Jaffrain G, Mari L, Maucha G, Soukup T (2004) The CORINE land cover 2000 project. EARSeL eProceedings 3(3):331-346

31. Batista e Silva F, Gallego J, Lavalle C (2013) A high-resolution population grid map for Europe. Journal of Maps 9(1):16-28

32. Britz W, Witzke HP (2008) Capri model documentation 2008: Version 2. Institute for Food and Resource Economicws. University of Bonn, Bonn

33. EC (2013) EU energy, transport and GHG emissions. Trends to 2050. Reference scenario 2013. Publications Office of the European Union. Luxembourg, Luxembourg

34. Anselin L (2001) Spatial econometrics. In: Baltagi BH (ed) A companion to theoretical econometrics. Blackwell Publishing Ltd, Malden, Ma, pp. 310-330

35. EuroStat (2011) Population projections. http://epp.eurostat.ec. europa.eu/statistics_explained/index.php/Population projections. Accessed 10/04/2014

36. Redding SJ, Sturm DM (2008) The costs of remoteness: Evidence from German division and reunification. Am Econ Rev 98(5):1766-1797 
37. Brakman S, Garretsen H, Van Marrewijk C, Oumer A (2012) The border population effects of EU integration. J Reg Sci 52(1):40-59

38. Jacobs-Crisioni C, Koomen E (2014) The infuence of national borders on urban development in border regions: An accessibility approach. Unpublished manuscript, VU University Amsterdam

39. Rich J, Brõcker J, Hansen CO, Korchenewych A, Nielsen OA, Vuk G (2009) Report on scenario, traffic forecast and analysis of traffic on the TEN-T, taking into consideration the external dimension of the union - TRANS-TOOLS version 2; model and data improvements. Copenhagen

40. Frost ME, Spence NA (1995) The rediscovery of accessibility and economic potential: the critical issue of self-potential. Environment and Planning A 27(11):1833-1848

41. Geurs KT, van Wee B (2004) Land-use/transport interaction models as tools for sustainability impact assessments of transport investments: Review and research directions. Eur J Transp Infrastruct Res 4(3):333-355

42. Wegener M (1998) Applied models of urban land use, transport and environment: state of the art and future developments. In: L. Lundqvist, L.G. Mattson, T.J. Kim (eds). Springer, Heidelberg,

43. Pfaffenbichler P, Emberger G, Shepherd S (2008) The integrated dynamic land use and transport model MARS. Networks and Spatial Economics 8:183-200

44. Zondag B, De Jong G (2005) The development of the TIGRIS XL model: a bottom-up to transport, land-use and the economy. In: Economic impacts of changes in accessibility, Edinburgh, 10/27/ 20052005.

45. Lavalle C, Mubareka S, Perpiña C, Jacobs-Crisioni C, Baranzelli C, Batista e Silva F, Vandecasteele I (2013) Configuration of a reference scenario for the land use modelling platform. Publications office of the European Union, Luxembourg

46. Batista e Silva F, Koomen E, Diogo V, Lavalle C (2014) Estimating demand for industrial and commercial land use given economic forecasts. PLoS One 9(3):e91991

47. EC (2013) Regional policy: Project examples. http://ec.europa.eu/ regional_policy/projects/stories/search.cfm?LAN=EN\&pay= ALL\&region $=$ ALL\&the $=60 \&$ type $=$ ALL\&per $=2$. Accessed 02/04/ 2014

48. Rietveld P (2001) Obstacles to openness of border regions in Europe. In: Van Geenhuizen M, Ratti R (eds) Gaining advantage from open borders. An active space approach to regional development. Ashgate, Aldershot, pp. 79-96

49. Ritsema van Eck J, Koomen E (2008) Characterising urban concentration and land-use diversity in simulations of future land use. Ann Reg Sci 42(1):123-140

50. Geurs K (2006) Accessibility, land use and transport. Utrecht University, Accessibility evaluation of land use and transport developments and policy strategies. Ph.D. Dissertation

51. Gløersen E, Lüer C (2013) Population data collection for European local administrative units from 1960 onwards. Spatial Foresight, Heisdorf

52. Stelder D, Groote P, De Bakker M (2013) Changes in road infrastructure and accessibility in Europe since 1960. Final report tender reference nr 2012.CE.16.BAT.040 European Commission

53. Kwan MP (1998) Space-time and integral measures of individual accessibility: A comparative analysis using a point-based framework. Geogr Anal 30(3):191-216 